Froes,T.R.'; Gonzalez, J.R.M. 2; Kanayama, L.M. ${ }^{3}$; Iwasaki, M. ${ }^{4}$; Fantoni, D. ${ }^{5}$

\section{2 - Ultra-sonografia intervencionista: drenagem percutânea de lesões renais e peri-renais. Estudos de casos}

1- Doutoranda do Departamento de Cirurgia da Faculdade de Medicina Veterinária e Zootecnia da Universidade de São Paulo, São Paulo-SP

2- Professora Doutora do Departamento de Ciências Veterinárias da Universidade Estadual de Londrina, Londrina-PR

3- Médica Veterinária da Faculdade de Medicina Veterinária e Zootecnia da Universidade de São Paulo, São Paulo-SP

4- Professora Titular da Faculdade de Medicina Veterinária e Zootecnia da Universidade de São Paulo, São Paulo-SP

5- Professora Doutora do Departamento de Cirurgia da Faculdade de Medicina Veterinária e Zootecnia da Universidade de São Paulo, São Paulo-SP

A ultra-sonografia intervencionista é um método diagnóstico ou terapêutico pouco invasivo, altamente eficiente e já consolidado na medicina humana, raramente utilizado na medicina veterinária. Como procedimentos intervencionistas incluem-se: biópsias aspirativas ou por fragmento, drenagem de cistos, abscessos e fluidos, introdução de cateteres, infusão de drogas e agentes de contraste para procedimentos radiográficos. O objetivo deste trabalho foi avaliarmos a eficácia de algumas técnicas intervencionitas eco-dirigidas como meio diagnóstico e terapêutico em enfermidades renais de cães e gatos. Foram avaliados as indicações, o melhor acesso, complicações e os resultados em 4 càes e 6 submetidos a intervenções no parênquima renal ou peri-renal. Todos os procedimentos foram realizados com o consentimento informado do proprietário. O exame ultra-sonográfico foi realizado com transdutores de 5,0 e $7,5 \mathrm{MHz}$, sob anestesia geral. Nos pacientes que não estavam sob antibioticoterapia, a mesma foi realizada na forma endovenosa imediatamente antes do procedimento, sendo a escollha da droga e posologia determinadas segundo os critérios do médico veterinário responsável pelo caso. Selecionamos agulhas hipodérmicas de diferentes tamanhos ou mandril metálico de cateteres endovenosos, de acordo com a profundidade da lesão. Após a anti-sepsia local, dirigimos a agulha / cateter até a lesão, acompanhando a introdução da mesma ultra-sonograficamente. Nos casos em que se pretendia atingir a pelve renal utilizamos um acesso no corte obliquo parasargital introduzindo a agulha a 45 graus na superficie ventro-lateral da curvatura maior do rim até atingir a região pélvica renal. Nos casos de drenagem dos pseudocistos a agulha era introduzida na posição em que se permitia a visualização de maior quantidade de líquido ou o mais distante possivel da regiào cortical renal. Nos casos de doença renal policística e dos abscessos renais a agullha era introduzida no interior dos cistos/abscessos. As técnicas eco-dirigidas realizadas foram: pielocentese diagnóstica (01 cão com suspeita de pielonefrite com dilatação pélvica, 01 gato com suspeita de pionefrose), pielografia anterógrada percutânea (01 gato com suspeita de processo obstrutivo ureteral), drenagem terapêutica de pseudocisto perinéfrico ( 03 gatos), drenagem de rins policísticos com objetivo de temporização (01 cão com dermatofibrose associado a cistoadenocarcinoma renal e 01 gato com doença renal polićstica) e drenagem diagnóstica e terapêutica de abscessos renais ( 02 cães), totalizando 10 intervençōes. Em nenhum caso foi observada complicação após o procedimento e em todos os animais a técnica atingiu o objetivo proposto. A drenagem percutânea eco-dirigida das lesões renais ou peri-renais é uma técnica rápida e segura no auxilio diagnóstico e terapêutico das enfermidades pélvicas, renais e peri-renais. 